\title{
Getting to Know You
}

\section{Steven Schwartz, DDS}

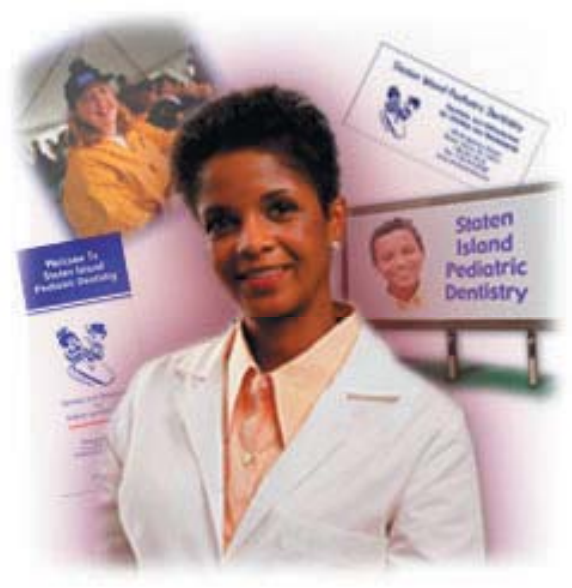

Abstract

This article provides an insight on two strategies involved in effectively promoting a dental practice. The strategies contain goals that are centered on name recognition and reputation enhancement. The name of the practice should be easy to pronounce, informative and recognizable. The use of effective marketing tools and activities are presented that facilitate these principles. Participation in the community through a variety of activities, offering quality expertise and maintaining a pleasant demeanor are key to enhancing the reputation of the dental practice and its staff.

Keywords: Dental practice promotion, Marketing a dental practice

Citation: Schwartz S. Getting to Know You. J Contemp Dent Pract 2002 November;(3)4:054-065.

(C) Seer Publishing 


\section{Introduction}

It is said, "If you build a better mousetrap, the world will beat a path to your door." But your patients can't beat a path to your door if they don't know where to find your door.

P.T. Barnum is known as the "prince of promotions." He attracted people to his circus with such attractions as parades, sideshows, and the midway. In addition to using bearded ladies, two headed animals, and giants, he lured customers to the circus with posters, fliers, and media events. He coined the phrase "Without promotion something terrible happens - nothing."

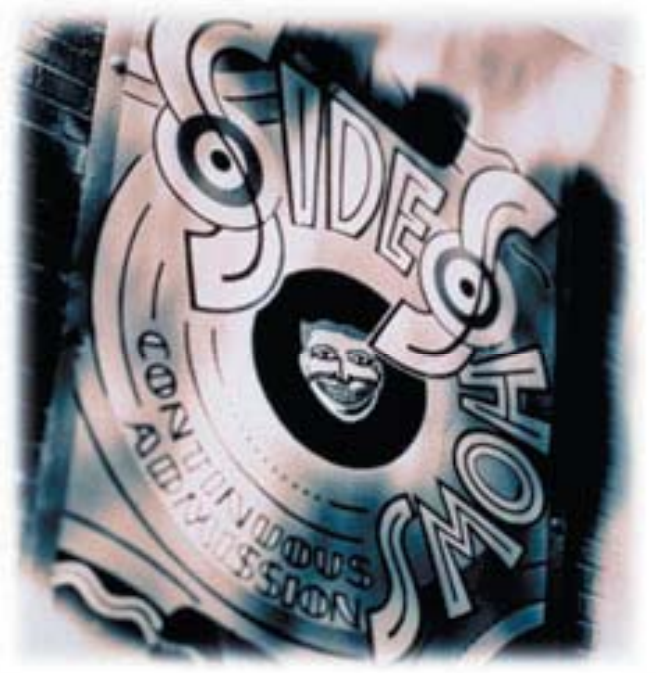

This article is devoted to teaching you how to prevent nothingness. How to promote your practice name so that when people think "dentist" (or a specialty of dentistry) your practice name immediately pops up.

\section{Promotion Goals}

The goals of a promotional program are to:

* Attract new patients, retain existing ones, and recapture those who have gone elsewhere

* Promote your practice name

* Promote an image

* Cultivate referrals

There are two strategies involved in effectively promoting your practice: name recognition and reputation enhancement. Newspaper and telephone directory advertisements, billboards, fliers, and your business cards contribute to name recognition. You enhance your reputation by the quality of service you provide to your patients and to your community.

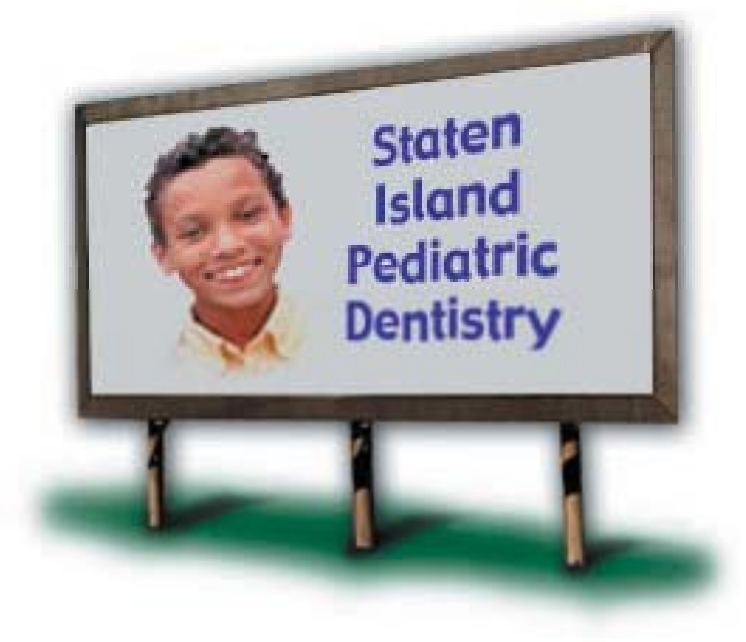

\section{Name Recognition}

\section{Naming Your Practice}

The first step in developing name recognition is creating a name that is easily recognized and associated with your dental practice. Your mother may be thrilled with your name especially since it begins with "Dr.", however, since "Dr." is at the beginning of every physician, dentist, podiatrist, veterinarian, psychologist, and philosopher, naming your practice after yourself does nothing to distinguish you from everyone else.

Your practice name announces who you are and what you stand for. It acts as a directory of services. Your practice name jumpstarts you to success or drags you down in failure. It lumps you with the rest of the crowd or helps you stand out.

What makes your practice name a good name?

* When it is easy to remember

* When it is simple to pronounce

* When it presents an easy understanding of what you do

* When it has a positive ring to it

* When it specifies the type of patient you serve

* When it describes a geographic area, while not being too limited 
For example, Steven Schwartz, DDS is pretty non-descriptive. Steven Schwartz, DMD is worse because some potential patients may not be familiar with the DMD degree in dentistry and may mistake the dentist for a physician. Even if patients recognize the degree, they do not realize the dentist specializes in pediatric dentistry. For some people the name "Schwartz" is difficult to pronounce and spell, i.e., Schwarz, Shwarz, and Shorts. There may be other doctors that go by the same last name.

As an alternative, the practice could be identified by a descriptive name such as Staten Island Pediatric Dentistry. It's easy to remember and pronounce. It announces the specialty services and gives a concise description of the category of patient (children) served in the practice. It describes the area served - the whole borough of Staten Island. Adopting the name Metro New York Pediatric Dentistry might give the impression to Staten Island residents that traveling to this office requires taking a ferry and train to New York City. If the name South Island Pediatric Dentistry were to be used, it might attract only those patients from the south shore of Staten Island. North shore patients might prefer seeking a pediatric dentist closer to them.

As a non-specialist, consider putting the words Family or General Dentistry as part of your practice name. The goal of your practice name is to define but not excessively limit the scope of your patient population.

\section{Logo Development}

A logo is your practice's fingerprint. It allows the public to easily identify you. It is not absolutely necessary to have a logo, but it does increase your marketability - just ask the executives at Coca and Pepsi Cola, McDonalds, and Microsoft. The advantages of a logo as a marketing tool are:

* It establishes practice name recognition

* It adds to your image

* It is an easy way to remind patients of what you do

* It helps you capture attention easily

Your logo should go on every piece of marketing material you use. Besides your business cards and stationery, it should go on your outdoor signs, promotional items, uniforms, recall cards, and billing statements. Your logo should be so identifiable with your practice that people can identify your practice without reading the name.

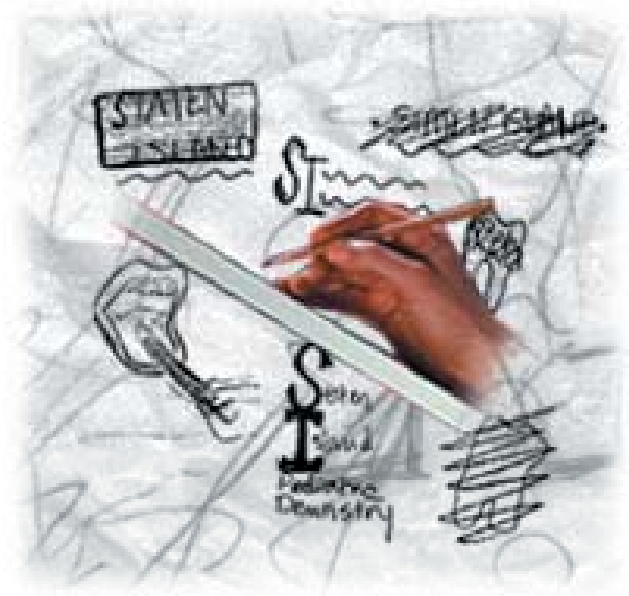

There are a variety of artistic choices for your logo. You can use pictures, caricatures, special fonts, and designs of your business name. If you use a picture or a symbol that is not an exact replica of your practice name, print the practice name somewhere around the logo so people can make the connection.

Software is available to design your own logo. However, in the long run it might be worthwhile to enlist the aid of an experienced graphic artist or marketing expert who can offer you several designs to choose from. Your logo is a very important part of your promotional program. Once you select a logo, you do not want to change it except for serious reasons.

\section{Business Cards}

Very often your business card provides people with their first impression of you. It conveys what you do and where you do it; it gives others an inkling of your personality and what you stand for. The goal of your promotional program is to make you stand out from the crowd. Therefore, your business card should stand out from other business cards. You can do this by:

* Using color stock

* Using plastic or mylar stock

* Making it in a nonrectangular shape

* Using a fold over

* Being unique 


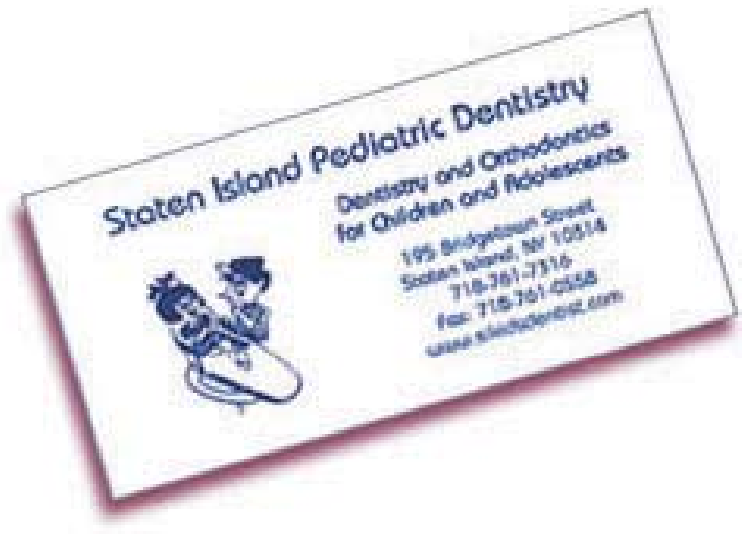

Your business card should have the following:

* Contact information; your name, practice name, address, phone, fax, e-mail, and web page url, if you have one

* Special degrees and advanced training

* Your logo

Consider the following to add pizzazz to your card for it to stand out from all of the others:

* Color stock and color ink

* Use the back for providing a brief biography and practice philosophy

* Use the back as an appointment card

* Use it as a promotional tool, such as a discount coupon

* Use easy to read print; test the size by giving samples to friends to read.

* DON'T USE ALL CAPITAL LETTERS AS THEY ARE DIFFICULT TO READ

* If there are changes in your information, order new cards. Do not cross out or put stickers over outdated information. Remember, this is your image we're talking about.

\section{Brochures}

The amount of information you can put on a business card is limited. A well-designed brochure can give potential patients a greater feel for what you and your practice has to offer.

They should be used whenever you are engaged in promotional activities, which will be most of your time. Distribute the brochures at any extra-office function in which you participate, i.e., health fairs, group lectures, and promotional events. Include them in welcome packets to new patients and display them in the reception and business area.
The brochure helps potential patients familiarize themselves with the office. It provides a more detailed description of you and your staff's educational background and advanced training. This not only increases confidence in your skills but also adds to practice value.

Include a group picture or caricature. But do not go overboard highlighting yourself. Emphasize to patients how they will benefit by coming to your practice. Describe how you can solve their problems and help them feel and look good. Include pictures of and endorsements from current satisfied patients.

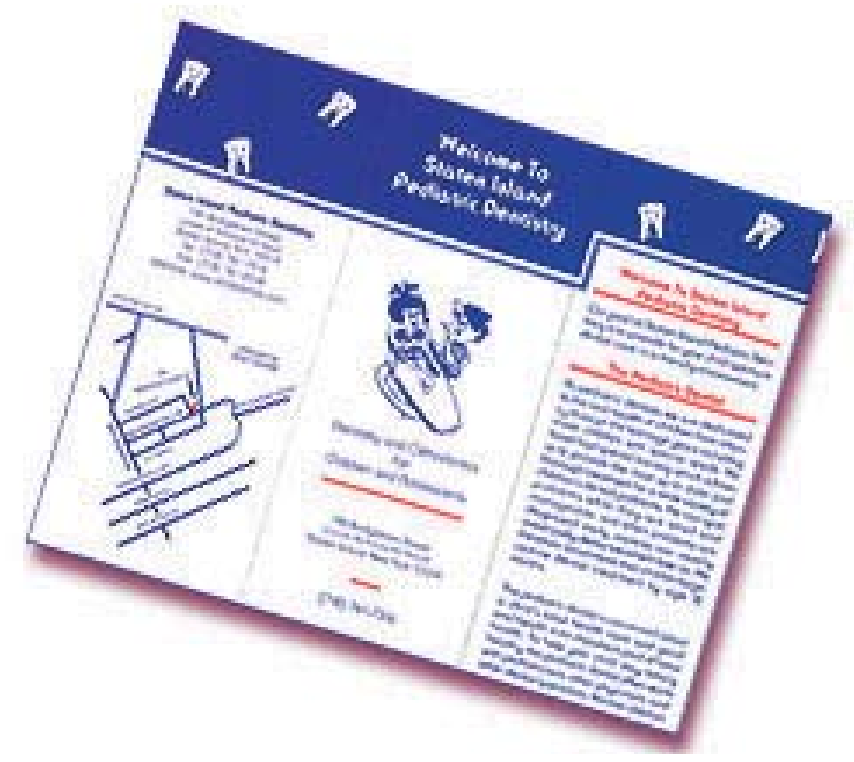

Have a call to action. Urge the patient to do something. Call for an appointment and/or refer a friend.

When designing the brochure:

* Use a headline, graphic, or photo to attract the reader

* Avoid using too much text; use bulleted information

* Use simple words

* Redo the brochure when the information is outdated

* Include contact information, directions and map to the office, and practice hours

Actual size, color, and layout are best designed in conjunction with a graphic artist. 


\section{Promotional Giveaways}

Your pediatric patients earn a trip to the toy box as a reward for good behavior, why not adults? Giveaways not only express appreciation, but when chosen and personalized appropriately, can be a great means of advertising.

Think of the pens provided for patient use in the front desk area. How often do you replenish them? I know in my office we go through 150 pens a month. It's not because they run out of ink but because patients unintentionally slip them into their pockets or pocketbooks. Consider this, if your name are not on those pens, they are a loss to the practice. If your name and phone number are on them, they are a promotional item.

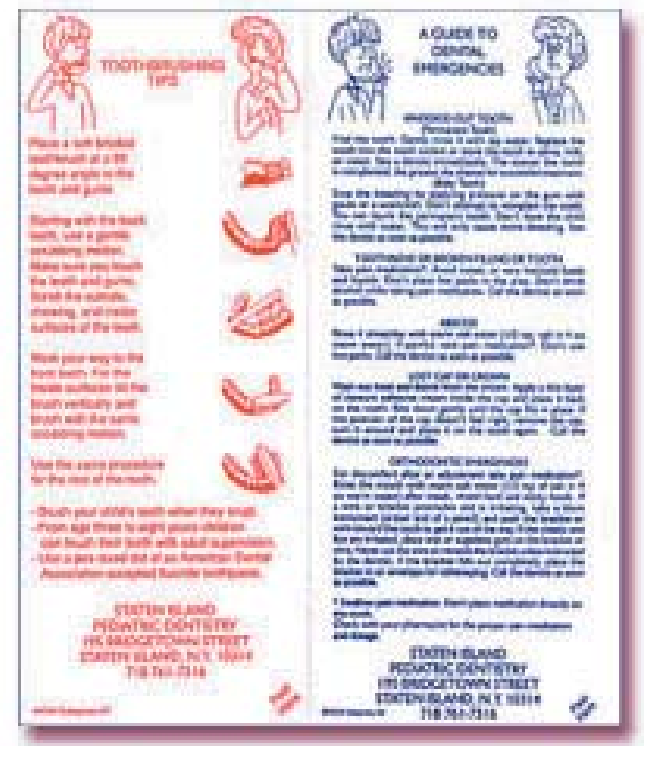

The same is true of toothbrushes. If they are given away without your practice name, they are an oral hygiene aid. But if personalized, every time someone goes into your patient's bathroom at home and sees them displayed in the toothbrush holder, they become a promotion for your practice.

There are many types of giveaways you can provide ranging from pens, to nail files, to jar openers, to magnets. To be effective as promotional items, there are four criteria they should meet:

* They should be affordable

* Your practice name can be printed on the item

* They can be of use to the patient

* They can be displayed so others will notice them
I like anything that sticks to a surface, i.e., magnets, stickers, or static stick ons. The Infostat shown adheres to any smooth surface, i.e., mirrors, walls, refrigerator doors, counters, etc. They provide useful dental health information to patients on such topics as oral hygiene instruction, emergency dental treatment, and care of orthodontic appliances. They can be customized with the practice name and logo. When patients display them on their refrigerators and bathroom mirrors, they are in full view of family and visitors making them a great promotional tool.

Do not limit the distribution of promotional items to the office. Enclose them in new patient packets and distribute them at community programs such as health fairs and school programs.

\section{Enhancing Your Reputation}

There are three ways you can enhance your reputation:

* Become an expert

* Be nice to others

* Provide terrific customer service

\section{Become an Expert}

If you are a dental school graduate, you are an expert on oral health issues when compared to the general population. By sharing your expertise with the public you enhance your reputation and effectively promote your practice. There are numerous avenues through which you can exhibit your knowledge of dentistry:

\section{- Present Seminars}

There are loads of community organizations that are always looking for speakers, i.e., fraternal lodges, school programs, religious organizations, or hospital community outreach programs. If they have monthly or bimonthly meetings, they need speakers. Presentations to the lay public can be very basic, covering topics ranging from dental health, new techniques, emergency care, to just answering questions about specific problems. (Suggestion: whenever someone asks you a question about a specific problem, give a very 
general answer and suggest they make an appointment to see you in your office).

Whenever you deliver a presentation, bring plenty of business cards, brochures, handouts, and promotional items all customized with your name and practice name. Have a badge made up with your name to wear during the presentation and while mingling with the audience.

\section{-Write an Article or Column for a Local Newspaper or Magazine}

A featured article on a specific topic or a weekly column published in a local newspaper or magazine gives you instant name recognition and establishes you as an expert for thousands of readers. It is amazing how hungry local newspapers are for featured articles. Use the same topics you present at your seminars for community groups, i.e., oral health, new techniques, and specific dental problems. If you are using a new technique or technology in your office, invite readers to your office to observe the technique.

Do you have doubts about your writing ability? Tape record your oral presentations to groups and individual patients and transcribe them into written form.

Unless you are a professional writer, do not expect payment for writing. However, most newspapers and magazines will allow you to include a brief biography and a means for readers to contact you. This is a great reason for you to create a practice website and create a virtual practice brochure.

\section{Be Nice}

People value nice people. Being in the presence of nice people makes others happy. Nice people are respected for their honesty, loyalty, and their willingness to serve others. The problem is you just can't tell others how nice you and your staff are. You have to walk the talk. You have to demonstrate it both outside and inside your office through external and internal acts of niceness.

\section{External Acts of Niceness}

An external act of niceness is anything that you do

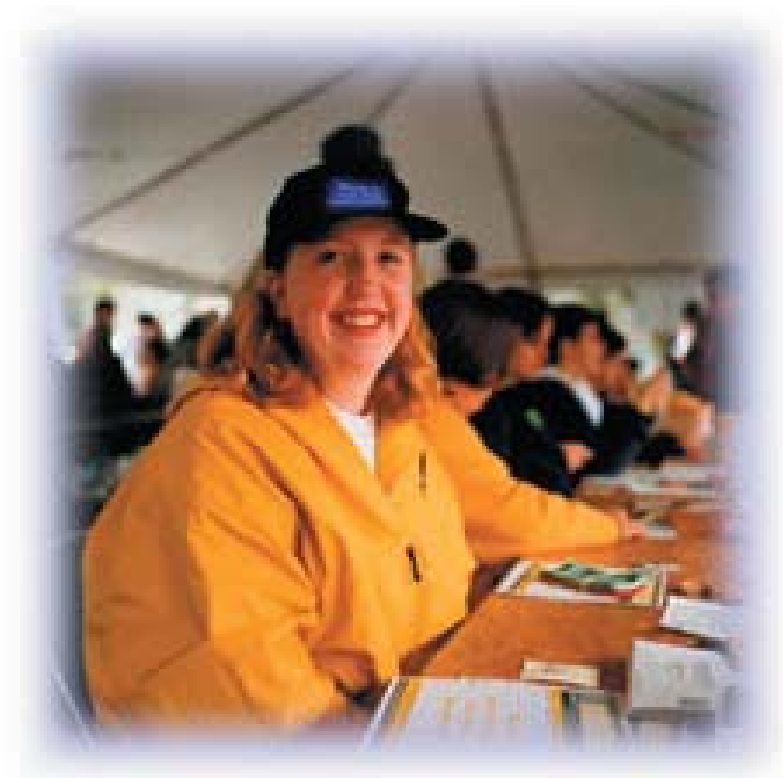

outside your office that demonstrates how nice you and your staff are. It involves volunteering your time, skills, and financial resources for community projects and nonprofit organizations. If you are new to your community, this along with writing and lecturing is the most efficient way to gain name recognition and reputation enhancement. Participation in these activities is not limited to you but should include your staff, especially if you have just opened a practice and you and your staff are sitting around looking at each other. Your participation should not be limited to use of your dental knowledge and skills. Your involvement as a member of the community is always appreciated. Types of activities you can volunteer for are:

* Sponsor scholarship programs for students interested in entering the dental profession.

* Volunteer your resources to youth sports programs in the area of injury prevention. Activities include lecturing on the use of mouthguards and supplying them for free. (This is a great way to get families to come to your office!)

* Volunteer your resources to shelters, food banks, hospitals, rescue squads, senior citizens, and child care centers. You do not have to limit your volunteerism to your dental skills. Many of these organizations need individuals to help run their daily activities.

* Close the office for the day and volunteer for Special Olympics or Habitat for Humanity type programs. Get your employees involved in volunteering for these activities. Not only will 
you be giving them the opportunity to feel good about themselves, but also they will think more of you.

* Ask your employees for their input as to what they would like to do. Give them a few hours off a week or a month to volunteer in community activities.

* Ask them if their favorite charities have programs you can support.

* When volunteering outside the office, provide everyone with caps, shirts, and/or jackets customized with your practice name and logo. It enhances the camaraderie among the staff, increases name recognition, and enhances your reputation.

Promotion or marketing is more than taking out a huge advertisement in the local newspaper or phone book. It is more than joining dental panels and advertising reduced fees. It is getting others to know you. It means sharing your professional and personal goals with people other than yourself. It is getting people - your staff, the public, and other dental professionals to discover what you have to offer. It is making others aware of how they will benefit by beating a path to your door.

\section{References}

1. 101 Ways to Promote Yourself; Raleigh Pinskey, Avon Books, Inc., 1997.

2. The Popcorn Report; Faith Popcorn, Harper Collins Publishers, 1992.

\section{About the Author}

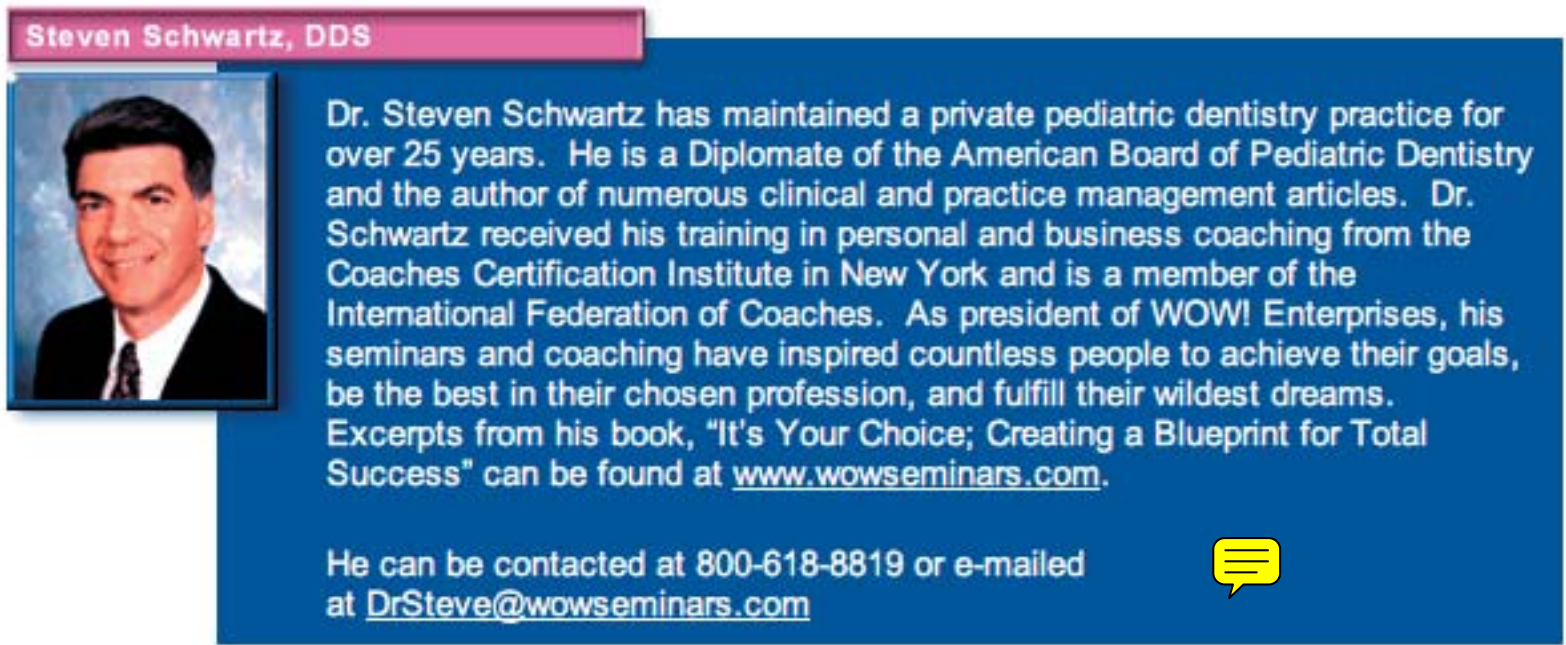

